\title{
SPECTRA OF COLLECTIVE EXCITATIONS AND LOW-FREQUENCY ASYMPTOTICS OF GREEN'S FUNCTIONS IN UNIAXIAL AND BIAXIAL FERRIMAGNETICS
}

\author{
DAnton Glushchenko, (D) Michail Kovalevsky, (D) Valentina Matskevych* \\ Kharkiv Institute of Physics and Technology \\ Academichna 1, Kharkiv, 61108, Ukraine \\ *E-mail: matskevych.vt@gmail.com
}

Received January 12, 2019; revised January 31, 2019; accepted February 21, 2019

The paper studies the dynamic description of uniaxial and biaxial ferrimagnetics with spin $s=1 / 2$ in alternative external field. The nonlinear dynamic equations with sources are obtained, on basis on which low-frequency asymptotics of two-time Green functions in the uniaxial and biaxial cases of the ferrimagnet are obtained. Energy models are constructed that are specific functions of Casimir invariants of the algebra of Poisson brackets for magnetic degrees of freedom. On their basis, the question of the stable magnetic states has been solved for the considered systems. These equations were linearized, an explicit form of the collective excitations spectra was found, and their character was analyzed. The article studies the uniaxial case of a ferrimagnet, as well as biaxial cases of an antiferromagnet, easy-axis and easy-plane ferrimagnets. It is shown that for a uniaxial antiferromagnet the spectrum of magnetic excitations has a Goldstone character. For biaxial ferrimagnetic materials, it was found that the spectrum has either a quadratic character or a more complex dependence on the wave vector. It is shown that in the uniaxial case of an antiferromagnet the Green function of the type $G_{s_{\alpha} s_{\beta}}(k, 0), G_{s_{\alpha} n_{\beta}}(k, 0)$ and $G_{s_{\alpha} s_{\beta}}(0, \omega)$ have regular asymptotic behavior, and the Green function of type $G_{n_{\alpha} n_{\beta}}(k, 0) \sim 1 / k^{2}$ and $G_{s_{\alpha} n_{\beta}}(0, \omega) \sim 1 / \omega, G_{n_{\alpha} n_{\beta}}(0, \omega) \sim 1 / \omega^{2}$ have a pole feature in the wave vector and frequency. Biaxial ferrimagnetic states have another type of the features of low-frequency asymptotics of the Green's functions. In the case of a ferrimagnet, the "easy-axis" of the asymptotic behavior of the Green functions $G_{s_{\alpha} s_{\beta}}(0, \omega), G_{s_{\alpha} n_{\beta}}(0, \omega), G_{n_{\alpha} n_{\beta}}(0, \omega)$, $G_{s_{\alpha} s_{\beta}}(k, 0), G_{s_{\alpha} n_{\beta}}(k, 0), G_{n_{\alpha} n_{\beta}}(k, 0)$ have a pole character. For the case of the "easy-plane" type ferrimagnet, the asymptotics of the Green functions $G_{s_{\alpha} n_{\beta}}(0, \omega), G_{n_{\alpha} n_{\beta}}(0, \omega), G_{s_{\alpha} n_{\beta}}(k, 0), G_{n_{\alpha} n_{\beta}}(k, 0)$ have a pole character, and the Green function $G_{s_{\alpha} s_{\beta}}(k, \omega)$ contains both the pole component and the regular part. A comparative analysis of the low-frequency asymptotics of Green functions shows that the nature of magnetic anisotropy significantly effects the structure of low-frequency asymptotics for uniaxial and biaxial cases of ferrimagnet. Separately, we note the non-Bogolyubov character of the Green function asymptotics for ferrimagnet with biaxial anisotropy $G_{n_{\alpha} n_{\beta}}(k, 0) \sim 1 / k^{4}$.

KEY WORDS: spin, ferromagnetic, spectra of collective excitations, Green's functions

\section{СПЕКТРИ КОЛЛЕКТИВНИХ ЗБУДЖЕНЬ ТА НИЗЬКОЧАСТОТНІ АСИМПТОТІКИ ФУНКЦЙ ГРІНА В ОДНОВІСНИХ ТА ДВОВІСНИХ ФЕРІМАГНЕТИКАХ}

А.В. Глущенко, М.Ю. Ковалевський, В.Т. Мацкевич

Національний науковий центр «Харківський фізико-технічний інститут» вул. Академічна, 1, м Харків, 61108, Украӥна

У роботі дано опис динаміки одновісних і двовісних ферімагнетиків зі спіном $s=1 / 2$ в зовнішньому змінному полі. Отримано нелінійні динамічні рівняння з джерелами, на основі яких обчислені низькочастотні асимптотики двочасових функцій Гріна феримагнетика в одновісному і двовісному випадках. Побудовано моделі енергії, які $є$ певними функціями інваріантів Казимира алгебри дужок Пуассона для магнітних ступенів свободи. На їх основі вияснено питання про стійкі магнітні стани таких магнітних систем. Проведена лінеаризація зазначених рівнянь, знайдений явний вигляд спектрів колективних збуджень і проаналізовано їх характер. У статті вивчені одновісний випадок феримагнетика, а також двовісні випадки антиферомагнетика, ферімагнетиків типу «легка вісь» i «легка площина». Показано, що для одновісного антиферомагнетика спектр магнітних збуджень має голдстоунівський характер. Для двовісних ферімагнетиків з'ясовано, що спектр має або квадратичний характер, або більш складну залежність від хвильового вектора. Показано, що в одновісному випадку антиферомагнетика функції Гріна типу $G_{s_{\alpha} s_{\beta}}(k, 0), G_{s_{\alpha} n_{\beta}}(k, 0)$ та $G_{s_{\alpha} s_{\beta}}(0, \omega)$ мають регулярний характер асимптотик, а функції Гріна типу $G_{n_{\alpha} n_{\beta}}(k, 0) \sim 1 / k^{2}$ та $G_{s_{\alpha} n_{\beta}}(0, \omega) \sim 1 / \omega, G_{n_{\alpha} n_{\beta}}(0, \omega) \sim 1 / \omega^{2}$ мають полюсну особливість по хвильовому вектору та частоті. Двовісні ферімагнітні стани мають особливості низькочастотних асимптотик функцій Гріна іншого типу. У разі феримагнетика «легка вісь» асимптотики функцій Гріна $G_{s_{\alpha} s_{\beta}}(0, \omega), G_{s_{\alpha} n_{\beta}}(0, \omega), G_{n_{\alpha} n_{\beta}}(0, \omega)$, $G_{s_{\alpha} s_{\beta}}(k, 0), G_{s_{\alpha} n_{\beta}}(k, 0), G_{n_{\alpha} n_{\beta}}(k, 0)$ мають полюсний характер. Для випадку феримагнетика типу «легка площина» асимптотики функцій Гріна $G_{s_{\alpha} n_{\beta}}(0, \omega), G_{n_{\alpha} n_{\beta}}(0, \omega), G_{s_{\alpha} n_{\beta}}(k, 0), G_{n_{\alpha} n_{\beta}}(k, 0)$ мають полюсний характер, а функція Гріна 
$G_{s_{\alpha} s_{\beta}}(k, \omega)$ містить як полюсну складову, так і регулярну частину. Проведений порівняльний аналіз низькочастотних асимптотик функцій Гріна показує істотний вплив характеру магнітної анізотропії на структуру низькочастотних асимптотик для одновісного і двовісного випадків феримагнетика. Окремо відзначимо, небоголюбівський характер асимптотики функції Гріна феримагнетика з двовісною анізотропією $G_{n_{\alpha} n_{\beta}}(k, 0) \sim 1 / k^{4}$.

КЛЮЧОВІ СЛОВА: спін, ферімагнетик, спектри колективних збуджень, функції Гріна

\section{СПЕКТРЫ КОЛЛЕКТИВНЫХ ВОЗБУЖДЕНИЙ И НИЗКОЧАСТОТНЫЕ АСИМПТОТИКИ ФУНКЦИЙ ГРИНА В ОДНООСНЫХ И ДВУХОСНЫХ ФЕРРИМАГНЕТИКАХ}

А.В. Глущенко, М.Ю. Ковалевский, В.Т. Мацкевич

Национальный научный центр «Харьковский физико-технический институт»

ул. Академическая, 1, г. Харьков, 61108, Украина

В работе дано описание динамики одноосных и двухосных ферримагнетиков со спином s=1/2 во внешнем переменном поле. Получены нелинейные динамические уравнения с источниками, на основе которых вычислены низкочастотные асимптотики двухвременных функций Грина ферримагнетика в одноосном и двухосном случаях. Построены модели энергии, которые являются определенными функциями инвариантов Казимира алгебры скобок Пуассона для магнитных степеней свободы. На их основе выяснен вопрос об устойчивых магнитных состояниях изучаемых магнитных систем. Проведена линеаризация указанных уравнений, найден явный вид спектров коллективных возбуждений и проанализирован их характер. В статье изучены одноосный случай ферримагнетика, а также двухосные случаи антиферромагнетика, ферримагнетиков типа «легкая ось» и «легкая плоскость». Показано, что для одноосного антиферромагнетика спектр магнитных возбуждений имеет голдстоуновский характер. Для двухосных ферримагнетиков выяснено, что спектр имеет либо квадратичный характер, либо более сложную зависимость от волнового вектора. Показано, что в одноосном случае антиферромагнетика функции Грина типа $G_{s_{\alpha} s_{\beta}}(k, 0), G_{s_{\alpha} n_{\beta}}(k, 0)$ и $G_{s_{\alpha} s_{\beta}}(0, \omega)$ имеют регулярный характер асимптотик, а функции Грина типа $G_{n_{\alpha} n_{\beta}}(k, 0) \sim 1 / k^{2}$ и $G_{s_{\alpha} n_{\beta}}(0, \omega) \sim 1 / \omega, G_{n_{\alpha} n_{\beta}}(0, \omega) \sim 1 / \omega^{2}$ имеют полюсную особенность по волновому вектору и частоте. Двухосные ферримагнитные состояния имеют особенности низкочастотных асимптотик функций Грина другого типа. В случае ферримагнетика «легкая ось» асимптотики функций Грина $G_{s_{\alpha} s_{\beta}}(0, \omega), G_{s_{\alpha} n_{\beta}}(0, \omega), G_{n_{\alpha} n_{\beta}}(0, \omega)$, $G_{s_{\alpha} s_{\beta}}(k, 0), G_{s_{\alpha} n_{\beta}}(k, 0), G_{n_{\alpha} n_{\beta}}(k, 0)$ имеют полюсной характер. Для случая ферримагнетика типа «легкая плоскость» асимптотики функций Грина $G_{s_{\alpha} n_{\beta}}(0, \omega), G_{n_{\alpha} n_{\beta}}(0, \omega), G_{s_{\alpha} n_{\beta}}(k, 0), G_{n_{\alpha} n_{\beta}}(k, 0)$ имеют полюсной характер, а функция Грина $G_{s_{\alpha} s_{\beta}}(k, \omega)$ содержит как полюсную составляющую, так и регулярную часть. Проведенный сравнительный анализ низкочастотных асимптотик функций Грина показывает существенное влияние характера магнитной анизотропии на структуру низкочастотных асимптотик для одноосного и двухосного случаев ферримагнетика. Отдельно отметим, небоголюбовский характер асимптотики функции Грина ферримагнетика с двухосной анизотропией $G_{n_{\alpha} n_{\beta}}(k, 0) \sim 1 / k^{4}$.

КЛЮЧЕВЫЕ СЛОВА: спин, ферримагнетик, спектры коллективных возбуждений, функции Грина

An effective method for studying magnetic systems is the Green function method. For a wide range of problems of statistical mechanics two-time Green functions [1-4] are used, whose knowledge allows one to investigate both the equilibrium state and the peculiarities of non-equilibrium processes, if deviations from equilibrium are small. When finding the Green's functions for condensed states, various approximate methods are used. These include the quasiparticle approximation, the random phase method, expansion in a small parameter and approximation with the uncontrolled nature of the approximation [2-4]. The calculation of the Green's functions in the low-frequency region is closely related to the behavior of the physical system at large times and possibly in two ways. One of them is the "memory" function method [5]. Another approach is the "sources" method, which was developed for superfluid media and degenerate magnetic systems with spin $s=1 / 2$ [6-9]. These methods were used to study the features of the two-time Green functions of isotropic superfluid and magnetic states, or with uniaxial magnetic anisotropy of equilibrium states.

In this paper we consider the influence of magnetic anisotropy on the collective behavior of uniaxial and biaxial ferrimagnetics. The aim of the research is to clarify the relationship of these factors with the spectra of collective excitations and the explicit form of the Green functions of these magnetics in the hydrodynamic limit, when the wave vector and frequency tend to zero. These data are useful in the study of the magnetic structure of these condensed media using cold neutrons.

The study of the dynamics of ferrimagnetic materials is based on the Hamiltonian formalism, which is widely used when considering various physical systems at the "hydrodynamic" stage of evolution [10] to describe slow nonequilibrium processes. In the following sections degenerate equilibrium states of ferrimagnetic materials with uniaxial and biaxial anisotropy are discussed. Nonlinear equations of the dynamics of the studied magnetic systems in an external alternating field are obtained. The spectra of collective excitations are found and low-frequency asymptotics of the two-time Green functions are obtained. The similarities and differences of such asymptotics, depending on the nature of the anisotropy of the physical system, are discussed. 


\section{DYNAMICS OF UNIAXIAL AND BIAXIAL FERRIMAGNETICS IN ALTERNATIVE EXTERNAL FIELD}

Consider multi-sublattice magnetics with spin $s=1 / 2$ in the case of uniaxial and biaxial $\mathrm{SO}(3)$ symmetry breaking of the equilibrium state. Normal equilibrium states of such magnetics are described by the Gibbs statistical operator

$$
\hat{w}(Y)=\exp \left(\Omega(Y)-Y_{0} \hat{H}-Y_{\alpha} \hat{S}_{\alpha}\right) .
$$

$\operatorname{Here} \Omega(Y)$ is the thermodynamic potential, which is a function of the thermodynamic forces $Y_{a}$ associated with additive integrals of motion. In the case of degenerate equilibrium states of magnets with one sublattice the Gibbs statistical operator has the form

$$
\hat{w}\left(Y, \hat{F}_{1}(\mathbf{m})\right)=\exp \left(\Omega(Y)-Y_{0} \hat{H}-Y_{\alpha} \hat{S}_{\alpha}-Y_{0} \nu \hat{F}_{1}(\mathbf{m})\right),
$$

where, according to the concept of quasi-averages, the source $\hat{F}_{1}(\mathbf{m})$ breaking symmetry is a functional of the spin density operator

$$
\hat{F}_{1}=\int d^{3} x m_{\alpha} \hat{s}_{\alpha}(\mathbf{x})
$$

Here $m_{\alpha}$ is the axis of spontaneous magnetic anisotropy. In the case of several magnetic sublattices, along with the source $\hat{F}_{1}$, there is another possibility of breaking the magnetic symmetry, which is determined by the source of the form

$$
\hat{F}_{2}=\int d^{3} x n_{\alpha} \hat{\Delta}_{\alpha}(\mathbf{x})
$$

where $\hat{\Delta}_{\alpha}(\mathbf{x})$ is the order parameter operator. In the limit $Y_{\alpha} \rightarrow 0$ the equilibrium state $\hat{w}\left(\hat{F}_{1}(\mathbf{m})\right)$ describes uniaxial symmetry breaking of the equilibrium state. In a magnetic with several sublattices, with $Y_{\alpha}=0$, the Gibbs statistical operator specifies the biaxial nature of the violation of the magnetic symmetry of the equilibrium state.

Two-time lagging Green functions are determined by the equality [1]:

$$
G_{a b}\left(\mathbf{x}, t ; \mathbf{x}^{\prime}, t^{\prime}\right)=-i \theta\left(t-t^{\prime}\right) S p \hat{w}\left[\hat{a}(\mathbf{x}, t), \hat{b}\left(\mathbf{x}^{\prime}, t^{\prime}\right)\right] .
$$

Here, the local operators in the Heisenberg representation $\hat{a}(\mathbf{x}, t)=e^{i \hat{H} t} \hat{a}(\mathbf{x}) e^{-i \hat{H} t}, \hat{b}(\mathbf{x}, t)=e^{i \hat{H} t} \hat{b}(\mathbf{x}) e^{-i \hat{H} t}$ and the Hamiltonian are definite functionals of the Bose operators of creation and annihilation. As we will see later, the structure of the spontaneous magnetic anisotropy of the Gibbs statistical operator will significantly affect the form of the low-frequency asymptotics of the Green functions. The linear response of a local physical quantity $\delta a_{\xi}(\mathbf{x}, t)$ to a weak external disturbance is

$$
\delta a_{\xi}(\mathbf{x}, t)=\int_{-\infty}^{+\infty} d t^{\prime} \int d^{3} x \delta \xi\left(\mathbf{x}^{\prime}, t^{\prime}\right) G_{a b}\left(\mathbf{x}-\mathbf{x}^{\prime}, t-t^{\prime}\right) .
$$

Here $\delta \xi(\mathbf{x}, t)$ is the potential of the interaction of the magnetic system with the external field. In the Fourier representation this ratio is written as

$$
\delta a_{\xi}(\mathbf{k}, \omega)=G_{a b}(\mathbf{k}, \omega) \delta \xi(\mathbf{k}, \omega)
$$

In the study of low-frequency asymptotics of Green's functions we do not use the formalism of quantum mechanics. To solve this problem it is sufficient for us to obtain the equations of the dynamics of the magnetics under study in the hydrodynamic limit. The linearized version of these equations connects the deviation of the local physical quantity $\delta a$ and the potential of the external field $\delta \xi$ and thus allows us to find the asymptotics of the two-time Green functions in the low-frequency $\omega \tau_{r}<<1$ and small wave vectors $k l<<1$ range. Here $\tau_{r}$ is the time of randomization (the time of establishing the local equilibrium of the magnetic system) and $l$ are the characteristic spatial scales of change in physical quantities. The full Hamiltonian of the magnetic system in the presence of an external field is of the form $H(t)=H+V(t)$. Here $H=\int d^{3} x e\left(\mathbf{x}, \varphi\left(x^{\prime}, t\right)\right)$ is the Hamiltonian of the magnetic system, which includes strong exchange interactions. Here $\varphi\left(\mathbf{x}^{\prime}, t\right)$ is a set of dynamic variables describing the magnetic system under study. The energy of interaction of the magnetic system with the external field $V(t)$ is

$$
V(t)=\int d^{3} x \delta \xi(\mathbf{x}, t) b(\mathbf{x}, t)
$$


where $b(\mathbf{x}, t)$ is the local physical quantity. We believe that the change in the external field is rather slow, so that the characteristic frequency of its change is small compared to $\tau_{r}^{-1}$. In this case, the physical system manages to adapt to the instantaneous values of the field. In the time domain $t \gg \tau_{r}$ the dependence on time of magnitude $b(\mathbf{x}, t)$ is

$$
b(\mathbf{x}, t) \underset{t>>\tau_{r}}{\longrightarrow} b\left(\mathbf{x}, \varphi\left(\mathbf{x}^{\prime}, t\right)\right) .
$$

For the physical systems studied in this work, the magnetic degrees of freedom $\varphi\left(\mathbf{x}^{\prime}, t\right)$ are the spin vector $s_{\alpha}$ and the antiferromagnetism vector $n_{\alpha}$, whose Poisson brackets are well known [11]:

$$
\begin{aligned}
& \left\{s_{\alpha}(\mathbf{x}), s_{\beta}\left(\mathbf{x}^{\prime}\right)\right\}=\delta\left(\mathbf{x}-\mathbf{x}^{\prime}\right) \varepsilon_{\alpha \beta \gamma} s_{\gamma}(\mathbf{x}), \\
& \left\{s_{\alpha}(\mathbf{x}), n_{\beta}\left(\mathbf{x}^{\prime}\right)\right\}=\delta\left(\mathbf{x}-\mathbf{x}^{\prime}\right) \varepsilon_{\alpha \beta \gamma} n_{\gamma}(\mathbf{x}) .
\end{aligned}
$$

Here $\delta(\mathbf{x})$ is the Dirac delta function. The algebra of the Poisson brackets (2) has a Casimir invariant $s_{\alpha}^{2}$. Extended algebra (2), (3) contains two Casimir invariants: $s_{\alpha} n_{\alpha}$ and $n_{\alpha}^{2}$. Below, in terms of these invariants, a model of the exchange interaction of a ferrimagnet will be constructed. Formulas (2), (3) allow us to establish the dynamics of uniaxial and biaxial ferrimagnetics:

$$
\dot{s}_{\alpha}=-\nabla_{k} s_{\alpha k}+\eta_{s_{\alpha}}, \quad \quad \dot{n}_{\alpha}=\varepsilon_{\alpha \beta \gamma}\left(\frac{\partial e}{\partial s_{\beta}}-\nabla_{k} \frac{\partial e}{\partial \nabla_{k} s_{\beta}}\right) s_{\gamma}+\eta_{n_{\alpha}} .
$$

Here $s_{o k}$ is the spin flux density, which has the form:

$$
s_{\alpha k}=\varepsilon_{\alpha \beta \gamma}\left(\frac{\partial e}{\partial \nabla_{k} s_{\beta}} s_{\gamma}+\frac{\partial e}{\partial \nabla_{k} n_{\beta}} n_{\gamma}\right) .
$$

When obtaining the spin flux density we took into account the $\mathrm{SO}(3)$ symmetry of the strong exchange interaction: $\left\{S_{\alpha}, H\right\}=0$. Sources due to the external field are determined by the formulas:

$$
\eta_{s_{a}}=\left\{s_{a}, V\right\}=\xi \varepsilon_{\alpha \beta \gamma}\left(\frac{\partial b}{\partial s_{\beta}} s_{\gamma}+\frac{\partial e}{\partial n_{\beta}} n_{\gamma}\right), \quad \eta_{n_{a}}=\left\{n_{a}, V\right\}=\xi \varepsilon_{\alpha \beta \gamma} \frac{\partial b}{\partial s_{\beta}} n_{\gamma} .
$$

In the used method of "sources" not always external variable fields can be given an obvious physical meaning. The role of a fictitious external field is to remove the local physical quantity of interest from the state of statistical equilibrium. By virtue of the definition of two-time Green's functions, these external fields are not included in the final expressions of the Green's functions.

Consider the equilibrium state of ferrimagnetic materials. The density of the exchange energy has $\mathrm{SO}(3)$ symmetry and depends on two vector quantities: the spin density and the antiferromagnetic order parameter

$$
e(\mathbf{s}, \mathbf{n})=e_{0}(\mathbf{s}, \mathbf{n})+e_{n}(\mathbf{s}, \mathbf{n}, \nabla \mathbf{s}, \nabla \mathbf{n}) .
$$

The model of the homogeneous part of this energy $e_{0}$ is chosen in the following form [12]:

$$
e_{0}\left(\varphi_{1}, \varphi_{2}\right)=-A \varphi_{1}^{2} / 2-C \varphi_{2}^{2} / 2+B \varphi_{1}^{4} / 4+D \varphi_{2}^{4} / 4+E \varphi_{1}^{2} \varphi_{2}^{2} / 2 .
$$

Energy density arguments $\varphi_{1}, \varphi_{2}$ are related to the Casimir invariants by equalities

$$
\varphi_{1}^{2}=(\mathbf{s n})^{2}=s_{\|}^{2}, \quad \varphi_{2}^{2}=s^{2}-(\mathbf{s n})^{2}=s_{\perp}^{2} .
$$

As two independent arguments of the homogeneous energy density $e_{0}=e_{0}\left(s_{\|}, s_{\perp}\right)$ it is convenient to choose the values of the transverse and longitudinal components of the spin with respect to the anisotropy axis $\mathbf{n}$ [13], which are determined by the equalities $s_{\alpha}=n_{\alpha} s_{\|}+m_{\alpha} s_{\perp}, s_{\alpha} n_{\alpha}=s_{\|}, \mathbf{n m}=0, \mathbf{m}=\mathbf{s}_{\perp} / s_{\perp}$. Conditionsofextremumandstability

$$
\left.\frac{\partial e_{0}}{\partial s_{\perp}}\right|_{0}=0,\left.\quad \frac{\partial e_{0}}{\partial s_{\|}}\right|_{0}=0
$$




$$
\frac{\partial^{2} e_{0}}{\partial s_{\perp}^{2}}>0, \quad \frac{\partial^{2} e_{0}}{\partial s_{\|}^{2}}>0, \quad \frac{\partial^{2} e_{0}}{\partial s_{\perp}^{2}} \cdot \frac{\partial^{2} e_{0}}{\partial s_{\|}^{2}}-\left(\frac{\partial^{2} e_{0}}{\partial s_{\perp} \partial s_{\|}}\right)^{2}>0
$$

allow us to find the corresponding values of the magnetic degrees of freedom in equilibrium.

The heterogeneous density of the exchange energy will be represented in the form of two quadratic forms:

$$
e_{n}=J_{\alpha \beta}(\mathbf{s}, \mathbf{n})\left(\nabla s_{\alpha}\right)\left(\nabla s_{\beta}\right) / 2+K_{\alpha \beta}(\mathbf{s}, \mathbf{n})\left(\nabla n_{\alpha}\right)\left(\nabla n_{\beta}\right) / 2 .
$$

Due to the transformational properties of spin vectors and antiferromagnetism and exchange energy density relative to time reversal transformations

$$
T s_{\alpha} T^{+}=-s_{\alpha}, \quad T \Delta_{\alpha} T^{+}=-\Delta_{\alpha}, \quad T e_{n} T^{+}=e_{n},
$$

for tensor exchange integrals $\hat{J}$ and $\hat{K}$ the relations are valid the relations

$$
J_{\alpha \beta}(\mathbf{s}, \mathbf{n})=J_{\alpha \beta}(-\mathbf{s},-\mathbf{n}), \quad K_{\alpha \beta}(\mathbf{s}, \mathbf{n})=K_{\alpha \beta}(-\mathbf{s},-\mathbf{n}) .
$$

From the symmetry conditions

$$
\left\{P_{k}, e_{n}\right\}=\nabla e_{n}, \quad\left\{L_{i}, e_{n}\right\}=\varepsilon_{i k l} x_{k} \nabla_{l} e_{n}, \quad\left\{S_{\alpha}, e_{n}\right\}=0,
$$

corresponding to the properties of translational invariance, as well as spatial and spin isotropy, we arrive at the following type of inhomogeneous exchange energy of a ferrimagnet:

$$
e_{n}=J^{(1)}\left(\nabla s_{\alpha}\right)^{2} / 2+J^{(3)}\left(n_{\alpha} \nabla s_{\alpha}\right)^{2} / 2+K^{(1)}\left(\nabla n_{\alpha}\right)^{2} / 2 .
$$

For positive definiteness of a non-uniform exchange energy, the constants of this exchange must be greater than zero: $J^{(1)}>0, J^{(3)}>0, K^{(1)}>0$. Using further the form of energy (8), we obtain the linearized equations of dynamics

$$
\begin{gathered}
\delta \delta_{\alpha}=-\varepsilon_{\alpha \beta \gamma}\left(J^{(1)} \Delta \delta \delta_{\beta} s_{\gamma}^{0}+J^{(3)} n_{\beta}^{0}\left(n_{\sigma}^{0} \Delta \delta s_{\sigma}\right) s_{\gamma}^{0}+K^{(1)} \Delta \delta n_{\beta} n_{\gamma}^{0}\right)+\xi \varepsilon_{\alpha \beta \gamma}\left(\frac{\partial b}{\partial s_{\beta}} s_{\gamma}^{0}+\frac{\partial b}{\partial n_{\beta}} n_{\gamma}^{0}\right) \\
\delta \dot{n}_{\alpha}=\varepsilon_{\alpha \beta \gamma} n_{\gamma}^{0}\left(\delta\left(\frac{\partial e_{0}}{\partial s_{\beta}}\right)-J^{(1)} \Delta \delta \delta_{\beta}+\xi \frac{\partial b}{\partial s_{\beta}}\right)+\varepsilon_{\alpha \beta \gamma} \frac{\partial e_{0}}{\partial s_{\beta}} \delta n_{\gamma} .
\end{gathered}
$$

Further, based on them, we obtain the spectra of magnetic excitations and calculate the low-frequency asymptotics of the Green functions of a ferrimagnetic with uniaxial and biaxial anisotropy.

\section{SPECTRA OF COLLECTIVE EXCITATIONS AND LOW-FREQUENCY ASYMPTOTICS OF GREEN'S FUNCTIONS IN UNIAXAIL FERRIMAGNETICS}

Consider magnetic states with uniaxial anisotropy, where in equilibrium $s_{\alpha}^{0}=0$. Equations (9) in this case are simplified and have the form:

$$
\begin{array}{r}
\delta_{\alpha}=-\varepsilon_{\alpha \beta \gamma} n_{\gamma}^{0}\left(K^{(1)} \Delta \delta n_{\beta}+\xi \varepsilon_{\alpha \beta \gamma} \frac{\partial b}{\partial n_{\beta}}\right), \\
\delta i_{\alpha}=\varepsilon_{\alpha \beta \gamma} n_{\gamma}^{0}\left(A \delta_{\beta}-J^{(1)} \Delta \delta \delta_{\beta}+\xi \frac{\partial b}{\partial s_{\beta}}\right) .
\end{array}
$$

For ferrimagnetics the deviation of a local quantity $a$ from an equilibrium state is of the form

$$
\delta a=\frac{\partial a}{\partial s_{\alpha}} \delta s_{\alpha}+\frac{\partial a}{\partial n_{\alpha}} \delta n_{\alpha} .
$$

From the linearized equations (10), we obtain Fourier-images of the deviation of the spin vector and the antiferromagnetism vector $\delta s_{\alpha}, \delta n_{\alpha}$ from equilibrium states: 


$$
\delta n_{\alpha}=\frac{1}{i \omega} \varepsilon_{\alpha \beta \gamma} n_{\gamma}^{0}\left(A \delta_{\beta}+\xi \frac{\partial b}{\partial s_{\beta}}\right), \quad \delta_{\alpha}=\xi D_{\alpha \beta}^{-1}\left(B_{\beta \mu} \frac{\partial b}{\partial s_{\mu}}+C_{\beta \mu} \frac{\partial b}{\partial n_{\mu}}\right),
$$

where matrices $\hat{B}, \hat{C}, \hat{D}$ are determined by formulas

$$
B_{\beta \mu}=k^{2} K^{(1)} \delta_{\beta \mu}^{\perp}\left(\mathbf{n}^{0}\right), \quad C_{\beta \mu}=-i \omega \varepsilon_{\beta \mu \nu} n_{v}^{0}, \quad D_{\beta \mu}(\mathbf{k}, \omega)=\omega^{2} \delta_{\beta \mu}-A K^{(1)} k^{2} \delta_{\beta \mu}^{\perp}\left(\mathbf{n}^{0}\right) .
$$

Using the written formulas, we obtain expressions for the low-frequency asymptotics of the two-time Green's functions of antiferromagnetics with uniaxial anisotropy:

$$
\begin{gathered}
G_{s_{\alpha} s_{\beta}}(\mathbf{k}, \omega)=\frac{k^{2} K^{(1)} \delta_{\alpha \beta}^{\perp}\left(\mathbf{n}^{0}\right)}{\Delta(\mathbf{k}, \omega)}, \\
G_{s_{\alpha} n_{\beta}}(\mathbf{k}, \omega)=-\frac{i \omega \varepsilon_{\alpha \beta \gamma} n_{\gamma}^{0}}{\Delta(\mathbf{k}, \omega)}, \quad G_{n_{\alpha} n_{\beta}}(\mathbf{k}, \omega)=\frac{A \delta_{\alpha \beta}^{\perp}\left(\mathbf{n}^{0}\right)}{\Delta(\mathbf{k}, \omega)} .
\end{gathered}
$$

Here are the notation $\Delta(\mathbf{k}, \omega)=\omega^{2}-k^{2} \kappa^{2}, \kappa^{2}=K^{(1)} A>0$ and $A=\left.2 \frac{\partial e_{0}}{\partial s^{2}}\right|_{0}$. The expressions given above coincide with the previously obtained Green's functions of [14]. The above formulas demonstrate a rather simple asymptotic structure of Green functions in uniaxial antiferromagnets. In particular, the relations are true

$$
\begin{gathered}
G_{s_{\alpha} s_{\beta}}(\mathbf{k}, 0)=-\frac{\delta_{\alpha \beta}^{\perp}\left(\mathbf{n}^{0}\right)}{A}, \quad G_{s_{\alpha} n_{\beta}}(\mathbf{k}, 0)=0, \quad G_{n_{\alpha} n_{\beta}}(\mathbf{k}, 0)=-\frac{\delta_{\alpha \beta}^{\perp}\left(\mathbf{n}^{0}\right)}{k^{2} K^{(1)}}, \\
G_{s_{\alpha} s_{\beta}}(0, \omega)=0, \quad G_{s_{\alpha} n_{\beta}}(0, \omega)=-\frac{i \varepsilon_{\alpha \beta \gamma} n_{\gamma}^{0}}{\omega}, G_{n_{\alpha} n_{\beta}}(0, \omega)=\frac{A \delta_{\alpha \beta}^{\perp}\left(\mathbf{n}^{0}\right)}{\omega^{2}}
\end{gathered}
$$

\section{SPECTRA OF COLLECTIVE EXCITATIONS AND LOW-FREQUENCY ASYMPTOTICS OF GREEN'S}

FUNCTIONS BIAXIAL FERRIMAGNETICS

We now consider the equilibrium states that are characterized by biaxial magnetic anisotropy with the axes $\mathbf{n}$ and $\mathbf{m}$. The conditions of extremum and stability (7) for the energy density model (6) lead to equilibrium states:

1) antiferromagnetic: $s_{\|}=0, s_{\perp}=0$. The state is stable if $Q=\left.\frac{\partial^{2} e_{0}}{\partial s_{\perp}^{2}}\right|_{0}=-A>0, \frac{\partial^{2} e_{0}}{\partial s_{\|}^{2}}=-C>0$;

2) ferrimagnetic of easy axis type: $s_{\|}=C / D, s_{\perp}=0$. The state is stable if $Q=-A+E s_{\|}^{2}>0, C>0$;

3) ferrimagnetic of easy plane type: $s_{\|}=0, s_{\perp}=A / B$. The state is stable if $Q=-A+3 B s_{\perp}^{2}>0$, $\frac{\partial^{2} e_{0}}{\partial s_{\|}^{2}}=-C+E s_{\perp}^{2}>0$

The state of a ferrimagnet with magnetic degrees of freedom in equilibrium $s_{\|} \neq 0, s_{\perp} \neq 0$ we do not consider in the article. The linearized equations of the dynamics of a magnetic system in an external field, valid near the above three biaxial equilibrium states, in the Fourier representation have the form:

$$
\begin{gathered}
i \omega \delta_{\alpha}=k^{2} \varepsilon_{\alpha \beta \gamma}\left\{s_{\perp}^{0} m_{\gamma}^{0} J^{(3)} n_{\sigma}^{0} \delta s_{\sigma} n_{\beta}^{0}+J^{(1)} s_{\gamma}^{0} \delta_{\beta}+K^{(1)} \delta n_{\beta} n_{\gamma}^{0}\right\}+\delta \xi_{\alpha \beta \gamma}\left(\frac{\partial b}{\partial s_{\beta}} s_{\gamma}^{0}+\frac{\partial b}{\partial n_{\beta}} n_{\gamma}^{0}\right) \\
i \omega \delta n_{\alpha}=l_{\alpha} Q m_{\sigma}^{0}\left\{\delta \delta_{\sigma}-s_{\|}^{0} \delta n_{\sigma}\right\}+\delta \xi \varepsilon_{\alpha \beta \gamma} \frac{\partial b}{\partial s_{\beta}} n_{\gamma}^{0} .
\end{gathered}
$$

Here $\mathbf{m} \times \mathbf{n}=\mathbf{l}$. Next, acting in a similar way, we obtain the expression of the two-time asymptotic behavior of the Green function in terms of the basis Green functions:

$$
G_{a b}(\mathbf{k}, \omega)=\frac{\partial a}{\partial s_{\alpha}} G_{s_{\alpha}, s_{\beta}}(\mathbf{k}, \omega) \frac{\partial b}{\partial s_{\beta}}+\frac{\partial a}{\partial n_{\alpha}} G_{n_{\alpha}, n_{\beta}}(\mathbf{k}, \omega) \frac{\partial b}{\partial n_{\beta}}+\frac{\partial a}{\partial s_{\alpha}} G_{s_{\alpha}, n_{\beta}}(\mathbf{k}, \omega) \frac{\partial b}{\partial n_{\beta}}+\frac{\partial a}{\partial n_{\alpha}} G_{n_{\alpha}, s_{\beta}}(\mathbf{k}, \omega) \frac{\partial b}{\partial s_{\beta}} .
$$

The general structure of the low-frequency asymptotics of the Green's functions can be represented as 


$$
\begin{gathered}
G_{s_{\alpha}, s_{\beta}}(\mathbf{k}, \omega)=D_{\alpha \gamma}^{-1}(\mathbf{k}, \omega) A_{\gamma \beta}(\mathbf{k}, \omega), \\
G_{n_{\alpha}, n_{\beta}}(\mathbf{k}, \omega)=-i Q l_{\alpha}^{0} m_{\sigma}^{0} D_{\sigma \rho}^{-1}(\mathbf{k}, \omega) B_{\rho \beta} / \omega, \\
G_{s_{\alpha}, n_{\beta}}(\mathbf{k}, \omega)=D_{\alpha \gamma}^{-1}(\mathbf{k}, \omega) B_{\gamma \beta} .
\end{gathered}
$$

The notation is entered here:

$$
\begin{gathered}
D_{\alpha \beta}(\mathbf{k}, \omega)=i \omega \delta_{\alpha \beta}+k^{2} s_{\perp}^{0} J^{(3)} l_{\alpha}^{0} n_{\beta}^{0}-k^{2} J^{(1)} \varepsilon_{\alpha \beta \gamma} s_{\gamma}^{0}-i k^{2} K^{(1)} Q m_{\alpha}^{0} m_{\beta}^{0} / \omega, \\
A_{\beta \gamma}(\mathbf{k}, \omega)=\frac{i k^{2} K^{(1)}}{\omega} \delta_{\beta \gamma}^{\perp}\left(\mathbf{n}^{0}\right)+\frac{k^{2}\left(s_{\|}^{0}\right)^{2} K^{(1)} Q}{\omega^{2}} m_{\beta}^{0} l_{\gamma}^{0}+\varepsilon_{\beta \gamma \gamma} s_{\rho}^{0}, B_{\beta \gamma}=\varepsilon_{\beta \gamma \rho} n_{\rho}^{0} .
\end{gathered}
$$

Let us analyze the Green's functions for the above three states of magnetism and find the explicit dependence of these functions on the wave vector and frequency. For the case of 1) antiferromagnet with biaxial anisotropy, the following form of the basis Green functions is obtained:

$$
\begin{gathered}
G_{s_{\alpha}, s_{\beta}}(\mathbf{k}, \omega)=\frac{k^{2} K^{(1)}}{\Delta(\mathbf{k}, \omega) \omega^{2}}\left(\omega^{2} \delta_{\alpha \beta}^{\perp}\left(\mathbf{n}^{0}\right)-k^{2} \kappa^{2} l_{\alpha}^{0} l_{\beta}^{0}\right), \\
G_{n_{\alpha}, n_{\beta}}(\mathbf{k}, \omega)=\frac{Q^{2} l_{\alpha}^{0} l_{\beta}^{0}}{\Delta(\mathbf{k}, \omega)}, \quad G_{s_{\alpha}, n_{\beta}}(\mathbf{k}, \omega)=-\frac{i \varepsilon_{\alpha \beta \gamma} n_{\gamma}^{0}}{\omega}+\frac{i k^{2} \kappa^{2} m_{\alpha}^{0} l_{\beta}^{0}}{\Delta(\mathbf{k}, \omega) \omega}=-G_{n_{\beta}, s_{\alpha}}(\mathbf{k}, \omega) .
\end{gathered}
$$

Here $\Delta(\mathbf{k}, \omega)=\omega^{2}-k^{2} \kappa^{2}$. The magnetic system in this state is characterized by the Goldstone spectrum $\omega=k \kappa$. Comparing these formulas with the Green's functions of a uniaxial antiferromagnet, we see that the asymptotics of the Green's functions $G_{s_{\alpha} s_{\beta}}(0, \omega), G_{s_{\alpha} n_{\beta}}(0, \omega)$ coincide. Asymptotics $G_{n_{\alpha} n_{\beta}}(k, 0), G_{n_{\alpha} n_{\beta}}(0, \omega)$ coincide qualitatively, but they have different anisotropy patterns. The asymptotics of the Green function of an antiferromagnetic with biaxial anisotropy $G_{s_{\alpha} s_{\beta}}(k, 0)$ can be represented as $G_{s_{\alpha} s_{\beta}}(k, 0)=G_{s_{\alpha} s_{\beta}}^{(r e g)}(k, 0)+G_{s_{\alpha} s_{\beta}}^{(p o l)}(k, 0)$. The regular part coincides with the Green function of a uniaxial antiferromagnet. The pole part has the form $G_{s_{\alpha} s_{\beta}}^{(p o l)}(k, 0)=\lim _{\omega \rightarrow 0} \frac{1}{\omega^{2}} k^{2} K^{(1)} l_{\alpha}^{0} l_{\beta}^{0}$. There is also no coincidence of the asymptotic behavior of the Green function $G_{s_{\alpha} n_{\beta}}(k, 0)$. For a uniaxial antiferromagnet, this value vanishes, and for a biaxial case it has a pole character $G_{s_{\alpha} n_{\beta}}(k, 0)=-i l_{\alpha}^{0} m_{\beta}^{o} \lim _{\omega \rightarrow 0} \frac{1}{\omega}$.

The case 2) ferrimagnetic of easy axis type: condition $\operatorname{det} \hat{D}=0$ leads to the excitation spectrum $\omega^{2}=k^{2} \kappa+k^{4} \kappa_{\|}^{2}$, here $\kappa_{\|}=J^{(1)} s_{\|}^{0}$. If the exchange integrals of the interaction differ significantly in magnitude, then in the limit of a) $K^{(1)} \gg J^{(1)}$ we obtain a linear spectrum $\omega=k \kappa$. In the other limiting case b) $K^{(1)} \ll J^{(1)}$ we arrive at a quadratic spectrum $\omega=k^{2} \kappa_{\|}$. In case a) the Green's basic functions coincide with the formulas of an antiferromagnet with biaxial anisotropy. In case $b$ ) these functions are:

$$
\begin{gathered}
G_{s_{\alpha}, n_{\beta}}(\mathbf{k}, \omega)=\frac{k^{2} \kappa_{\|} \delta_{\alpha \beta}^{\perp}\left(\mathbf{n}^{0}\right)}{\Delta_{\|}(\mathbf{k}, \omega)}-\frac{i \omega \varepsilon_{\alpha \beta \gamma} n_{\gamma}^{0}}{\Delta_{\|}(\mathbf{k}, \omega)}, \\
G_{s_{\alpha}, s_{\beta}}(\mathbf{k}, \omega)=s_{\|}^{0} G_{s_{\alpha}, n_{\beta}}(\mathbf{k}, \omega), \quad G_{n_{\alpha}, n_{\beta}}(\mathbf{k}, \omega)=-\frac{Q l_{\alpha}^{0} l_{\beta}^{0}}{\Delta_{\|}(\mathbf{k}, \omega)} .
\end{gathered}
$$

Here $\Delta_{\|}(\mathbf{k}, \omega)=\omega^{2}-k^{4} \kappa_{\|}^{2}$. Let us give particular cases of the form of the asymptotics of the Green functions:

$$
\begin{aligned}
G_{s_{\alpha}, n_{\beta}}(\mathbf{k}, 0) & =-\frac{\delta_{\alpha \beta}^{\perp}\left(\mathbf{n}^{0}\right)}{k^{2} \kappa_{\|}}, & G_{s_{\alpha}, n_{\beta}}(0, \omega) & =-\frac{i \varepsilon_{\alpha \beta \gamma} n_{\gamma}^{0}}{\omega}, \\
G_{n_{\alpha}, n_{\beta}}(\mathbf{k}, 0) & =\frac{Q l_{\alpha}^{0} l_{\beta}^{0}}{k^{4} \mathcal{K}_{\|}^{2}}, & G_{n_{\alpha}, n_{\beta}}(0, \omega) & =-\frac{Q l_{\alpha}^{0} l_{\beta}^{0}}{\omega^{2}} .
\end{aligned}
$$

We see that the asymptotics of the basis Green's function $G_{n_{\alpha}, n_{\beta}}(\mathbf{k}, 0)$ with respect to the wave vector has a nonBogolyubov character. Note that such a stronger feature of the asymptotic behavior of the Green function $G_{n_{\alpha}, n_{\beta}}(\mathbf{k}, 0)$ does not contradict the inequality $G_{n_{\alpha}, n_{\beta}} \geq 1 / k^{2}$ [7]. This theorem sets a restriction on the asymptotic behavior of Green's functions from below for $k \rightarrow 0$. 
For the case 3) ferrimagnetic of the easy plane type the basis Green functions are found, in which to simplify the calculations we neglected the exchange integral $J^{(3)}$ :

$$
\begin{gathered}
G_{s_{\alpha}, n_{\beta}}(\mathbf{k}, \omega)=\frac{k^{2} \kappa_{\perp} n_{\alpha}^{0} m_{\beta}^{0}}{\Delta_{\perp}(\mathbf{k}, \omega)}+i \omega\left(\frac{m_{\alpha}^{0} l_{\beta}^{0}}{\Delta(\mathbf{k}, \omega)}-\frac{l_{\alpha}^{0} m_{\beta}^{0}}{\Delta_{\perp}(\mathbf{k}, \omega)}\right), \\
G_{n_{\alpha}, n_{\beta}}(\mathbf{k}, \omega)=\frac{Q l_{\alpha}^{0} l_{\beta}^{0}}{\Delta(\mathbf{k}, \omega)}, \\
G_{s_{\alpha}, s_{\beta}}(\mathbf{k}, \omega)=k^{2} K^{(1)}\left(\frac{m_{\alpha}^{0} m_{\beta}^{0}}{\Delta(\mathbf{k}, \omega)}+\frac{l_{\alpha}^{0} l_{\beta}^{0}}{\Delta_{\perp}(\mathbf{k}, \omega)}\right)-\frac{k^{2} \kappa_{\perp} s_{\perp}^{0} \delta_{\alpha \beta}^{\perp}\left(\mathbf{m}^{0}\right)}{\Delta_{\perp}(\mathbf{k}, \omega)}+\frac{i\left(k^{4} \kappa_{\perp} K^{(1)} n_{\alpha}^{0} l_{\beta}^{0}-\omega^{2} s_{\perp}^{0} \varepsilon_{\alpha \beta \gamma} m_{\gamma}^{0}\right)}{\Delta_{\perp}(\mathbf{k}, \omega) \omega} .
\end{gathered}
$$

Here $\Delta(\mathbf{k}, \omega)=\omega^{2}-k^{2} \kappa^{2}, \Delta_{\perp}(\mathbf{k}, \omega)=\omega^{2}-k^{4} \kappa_{\perp}^{2}, \kappa_{\perp}=J^{(1)} s_{\perp}^{0}$. Such a magnetic state has two spectra of collective excitations $\omega=k \kappa$ and $\omega=k^{2} \kappa_{\perp}$. We write out a particular form of the asymptotics of the basis Green's functions using (14):

$$
\begin{gathered}
G_{s_{\alpha}, n_{\beta}}(\mathbf{k}, 0)=-\frac{n_{\alpha}^{0} m_{\beta}^{0}}{k^{2} \kappa_{\perp}}, \quad G_{s_{\alpha}, n_{\beta}}(0, \omega)=-\frac{i \varepsilon_{\alpha \beta \gamma} n_{\gamma}^{0}}{\omega}, \\
G_{n_{\alpha}, n_{\beta}}(\mathbf{k}, 0)=-\frac{l_{\alpha}^{0} l_{\beta}^{0}}{k^{2} K^{(1)}}, \quad G_{n_{\alpha}, n_{\beta}}(0, \omega)=\frac{Q l_{\alpha}^{0} l_{\beta}^{0}}{\omega^{2}}, \quad G_{s_{\alpha}, s_{\beta}}(\mathbf{k}, \omega)=-\frac{i s_{\perp}^{0} \varepsilon_{\alpha \beta \gamma} m_{\gamma}^{0}}{\omega} .
\end{gathered}
$$

From (14) it also follows that the asymptotic behavior of the Green function $\lim _{\omega \rightarrow 0} G_{s_{\alpha}, s_{\beta}}(\mathbf{k}, \omega)$ can be represented as two terms $\lim _{\omega \rightarrow 0} G_{s_{\alpha}, s_{\beta}}(\mathbf{k}, \omega)=G_{s_{\alpha}, s_{\beta}}^{(r e g)}(\mathbf{k}, 0)+G_{s_{\alpha}, s_{\beta}}^{(p o l)}(\mathbf{k}, \omega \rightarrow 0)$. The first of these is regular at $\omega \rightarrow 0$, and the second term contains a pole feature in frequency:

$$
\begin{gathered}
G_{s_{\alpha}, s_{\beta}}^{(r e g)}(\mathbf{k}, \omega)=\frac{K^{(1)} l_{\alpha}^{0} l_{\beta}^{0}}{k^{2} \kappa_{\perp}^{2}}-\frac{s_{\perp}^{0} \delta_{\alpha \beta}^{\perp}\left(\mathbf{m}^{0}\right)}{k^{2} \kappa_{\perp}}-\frac{K^{(1)} m_{\alpha}^{0} m_{\beta}^{0}}{\kappa^{2}}, \\
G_{s_{\alpha}, s_{\beta}}^{(p o l)}(\mathbf{k}, \omega \rightarrow 0)=-\frac{i K^{(1)} n_{\alpha}^{0} l_{\beta}^{0}}{\omega \kappa_{\perp}} .
\end{gathered}
$$

In the limit $s_{\perp}^{0} \rightarrow 0$ the asymptotics of the basis Green's functions (14) coincide with formulas (13) for the antiferromagnetic equilibrium state. A similar limit $s_{\|}^{0} \rightarrow 0$ does not lead to expression (14) to formulas of a biaxial antiferromagnet, since, in obtaining these formulas, we completely neglected the influence of the exchange integral $K^{(1)}$.

\section{CONCLUSIONS}

The article considers the problem of the influence of a weak alternating field on the evolution of uniaxial and biaxial ferrimagnets and nonlinear dynamic equations that take into account the properties of the $\mathrm{SO}(3)$ symmetry of exchange interactions. On the basis of these equations, the "hydrodynamic" asymptotics of the two-time Green functions are calculated in explicit form with respect to the wave vector and frequency. The presented research results demonstrate the importance of the specific anisotropy of the magnetic system in the description of the collective properties of the studied magnets. An analysis of the asymptotic behavior of the Green function of the type $G_{n_{\alpha} n_{\beta}}(k, 0) \sim 1 / k^{4}$ in a ferrimagnet with biaxial anisotropy shows that such features can arise in other magnetic states for which the contribution of the zero approximation in gradients to the linearized equation of the order parameter is absent. These words also allow you to know the spectra of the collective magnetic waves, the character of the magnetic anisotropic characteristics of the Grain that give you the ability to design the neutron neutron processes in the magnitudes of the neutrons in magnetics.

Anton Glushchenko (1) https://orcid.org/0000-0003-2574-6688,

\section{ORCID IDs}

Michail Kovalevsky (1) https://orcid.org/0000-0002-9224-5288,

Valentina Matskevych 1 https://orcid.org/0000-0001-9368-500X

\section{REFERENCES}

[1]. N.N. Bogolyubov and S.V. Tyablikov, DAN USSR, 126, 53-56 (1959).(in Russian)

[2]. A.A. Abrikosov, L.P. Gorkov and I.E. Dzyaloshinsky, Methods of quantum field theory in static physics, (Fizmatgiz, Moscow, 1962), p. 444. (in Russian) 
[3]. V.G. Bar'yakhtar, V.N. Krivoruchko and D.A. Yablonsky, Green's functions in the theory of magnetism, (Naukova Dumka, Kyiv, 1984), p. 336. (in Russian)

[4]. G.D. Mahan, Many-particle physics, 2nd Edition, (Plenum, New York, 1990), p. 1032.

[5]. A.I. Akhiezer and S.V. Peletminsky, Methods of statistical mechanics, (Nauka, Moscow, 1977), p. 338.(in Russian)

[6]. N.N. Bogolyubov, M.Yu. Kovalevsky, A.M. Kurbatov, S.V. Peletminsky and A.N. Tarasov, Successes of physical sciences, 159(12) 585-620, (1989), doi: 10.3367/UFNr.0159.198912a.0585 (in Russian)

[7]. N.N. Bogolyubov, Preprint R-1395 JINR, (JINR, Dubna, 1963). (in Russian)

[8]. B.I. Halperin and W.M. Saslow, Physical Review B, 16(5) 2154-2162, (1977).

[9]. Z.M. Galasiewicz, Journal of low temperature physics, 57(1-2) 123-150, (1984), doi: 10.1007/BF00681519

[10]. M.Y. Kovalevskii and A.A. Rozhkov, Physica A: Statistical Mechanics and its Applications, 216(1-2) 169-184, (1995), doi: 10.1016/0378-4371(94)00293-3

[11]. I.E. Dzyaloshinskii and G.E. Volovick, Annals of Physics, 125(1) 67-97, (1980).

[12]. K. Kaneko, H. Onodera, H. Yamauchi, T. Sakon, M. Motokawa and Y. Yamaguchi, Physical Review B, 68(1) 012401, (2002), doi: 10.1103/PhysRevB.68.012401

[13]. E.A. Turov, A.V. Kolchanov, V.V. Menshenin, I.F. Mirsaev and V.V. Nikolaev, Symmetry and physical properties of antiferromagnets, (Fizmatlit, Moscow, 2001), p. 560.(in Russian)

[14]. A.A. Isaev, M.Yu. Kovalevsky and S.V. Peletminsky, Theoretical and Mathematical Physics, 95(1) 404-415, (1993), doi: org/10.1007/BF01015894 